\title{
A Compact 5.5 GHz Band-Rejected UWB Antenna Using Complementary Split Ring Resonators
}

\author{
M. M. Islam, ${ }^{1}$ M. R. I. Faruque, ${ }^{1}$ and M. T. Islam ${ }^{2}$ \\ ${ }^{1}$ Space Science Centre (ANGKASA), Universiti Kebangsaan Malaysia, 43600 Bangi, Selangor, Malaysia \\ ${ }^{2}$ Department of Electrical, Electronic and Systems Engineering, Universiti Kebangsaan Malaysia, 43600 Bangi, Selangor, Malaysia
}

Correspondence should be addressed to M. R. I. Faruque; rashedgen@yahoo.com

Received 5 March 2014; Accepted 28 April 2014; Published 22 May 2014

Academic Editor: Jaume Anguera

Copyright (c) 2014 M. M. Islam et al. This is an open access article distributed under the Creative Commons Attribution License, which permits unrestricted use, distribution, and reproduction in any medium, provided the original work is properly cited.

\begin{abstract}
A band-removal property employing microwave frequencies using complementary split ring resonators (CSRRs) is applied to design a compact UWB antenna wishing for the rejection of some frequency band, which is meanwhile exercised by the existing wireless applications. The reported antenna comprises optimization of a circular radiating patch, in which slotted complementary SRRs are implanted. It is printed on low dielectric FR4 substrate material fed by a partial ground plane and a microstrip line. Validated results exhibit that the reported antenna shows a wide bandwidth covering from 3.45 to more than $12 \mathrm{GHz}$, with a compact dimension of $22 \times 26 \mathrm{~mm}^{2}$, and VSWR $<2$, observing band elimination of $5.5 \mathrm{GHz}$ WLAN band.
\end{abstract}

\section{Introduction}

The formation of the split ring resonator (SRR) was discovered by Pendry for the first time to construct metamaterials where the electromagnetic (EM) wave conducted in an opposite route according to the convectional manner [14]. The band-rejected properties are applied to extrude the undesired band for an ultrawide band antenna. In the field of short-distance wireless communication, a new opportunity is introduced by the Federal Communications Commission (FCC), with the announcement of $3.1-10.6 \mathrm{GHz}$ frequency band for unlicensed radio communication [5]. Antennas include a spacious range of cellular mobile phones in the running society resulted in enhancing concerns combining its harmful radiation [6-8]. Because of having the opportunities of high data transmission rate, inexpensiveness, simplicity, and low spectral power density, UWB technology has been considered as one of the most fruitful candidates in wireless communications. Conventional antennas used parasitic strips, SRRs, and different slots to create rejected frequency bands. Some of these antennas had relatively large size or did not cover $5.5 \mathrm{GHz}$ band rejection. Some UWB antennas are designed with band-notched, which are referred to below to face the effect created with respect to the frequency interference operating in WLAN $(5.15-5.825 \mathrm{GHz})$ [9] as well as WiMAX $(5.25-5.85 \mathrm{GHz})$ systems.
A new ring antenna fed by a microstrip line was proposed for UWB communication, where a proximity-coupled configuration was adopted [10]. The average gain was $2.93 \mathrm{dBi}$ where the overall antenna dimension was $44 \times 40 \mathrm{~mm}^{2}$. An UWB monopole antenna was presented with band-rejected features in the reported reference [11]. Two identical square complementary split ring resonators (CSRRs) were inserted on the radiating patch to achieve rejected bands. The antenna dimensions were $30 \mathrm{~mm} \times 34 \mathrm{~mm}$ which was too large than our proposed antenna of compact size $22 \mathrm{~mm} \times 26 \mathrm{~mm}$. A miniaturized crescent microstrip antenna was proposed with an elliptical radiating patch by carving a circular hole inside symmetrically for UWB application [12]. The antenna had a relatively large size $\left(45 \times 50 \mathrm{~mm}^{2}\right)$ and did not cover the upper edge frequency of the UWB. A tapered-shape slot antenna was proposed for ultrawide band applications [13]. For the radiating patch and the slot, different types of shapes such as triangular, rectangular, elliptical circular, and square were compared to each other. The antenna achieved ultrawide band properties with medium average peak gain of $3.6 \mathrm{dBi}$. Some antennas were proposed based on SRRs with metamaterials characteristics [14-16].

In [17], a monopole antenna was presented with single notched-band properties for UWB application. An openlooped resonator is inserted to originate notched-band 


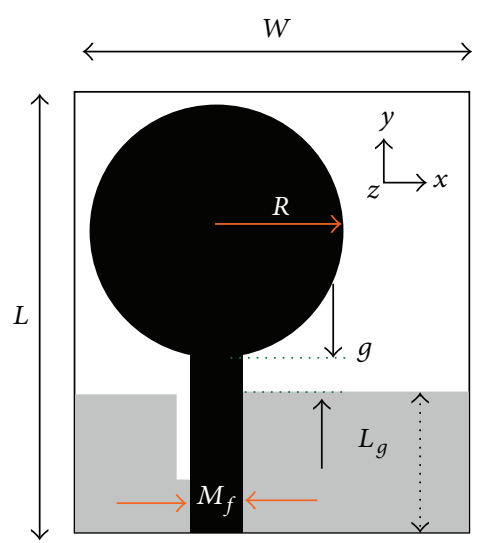

(a)



(b)

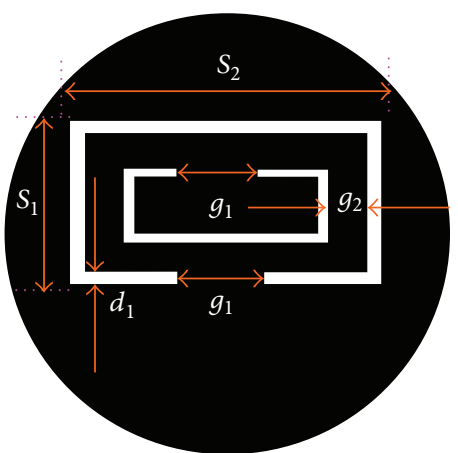

(c)

FIGURE 1: Structures of the (a) UWB antenna, (b) proposed band-rejected antenna, and (c) band-rejection layout.

centered at $5 \mathrm{GHz}$ at the center of the reported fork-shaped antenna, where the antenna dimension is $35 \times 30 \mathrm{~mm}^{2}$. A compact monopole antenna was presented with standard notched-band properties where the antenna dimensions were $30 \mathrm{~mm} \times 35 \mathrm{~mm}$ [18]. In order to originate a notch frequency band covering from 5.12 to $6.08 \mathrm{GHz}$, a vertical coupling strip was inserted at the centre of the radiating slot patch. A notched-band design was presented for UWB antennas [19]. Complementary split ring resonators (CSSRs) were etched in the T-stub region of a CPW feed in the reported antenna to generate a notch frequency band of $5-6 \mathrm{GHz}$ where the antenna dimensions were $33 \mathrm{~mm} \times 35 \mathrm{~mm}$.

A novel tapered slot antenna was proposed with a band-notched function for ultrawide band radios [20]. The reported antenna of $50 \times 50 \mathrm{~mm}^{2}$ dimension attained ultrawide band characteristics with a band-notched of 4.66.2 GHz, implanting an Archimedean spiral-shaped slot into a microstrip-slot line feeding that belongs to open-circuit circular stub. In [21], genetic algorithm (GA) was applied to face various difficulties of microstrip antennas. In order to introduce and regulate notch bands, complex filter structures are required for some of the reported designs, in spite of having notched-band properties. On the other hand, the notched frequency bands of several reported antennas are more spacious than the desired band ranging from 5.15 to $5.825 \mathrm{GHz}$ for WLAN applications, ending in downfall of holding lower signal quality and information.

An eliminated 5.5 GHz WLAN band microstrip antenna with slotted complementary SRRs that attains a compact UWB profile physically belonging to nearly omnidirectional radiation characteristics, gain, and reasonable current distribution is presented in this study. The mentioned bandrejected antenna is made of circular radiating patch with complementary SRRs slots and a partial ground plane containing a rectangular slot on the upper portion, generating an ultrawide bandwidth ranging from 3.45 to more than $12 \mathrm{GHz}$. The antenna formation is smooth with simple design and comfortable fabrication. Slotted CSRRs are inserted inside the circular patch to generate a notch frequency band for filtering out $5.5 \mathrm{GHz}$ WLAN band. All the design parameters are related to create band rejection. The thickness and the split gap of the edges of the CSRR rings exhibit band-rejection UWB characteristic creating $5.5 \mathrm{GHz}$ rejection band. By virtue of significant selection of slotted CSRRs parameters, it is observed that the reported antenna can obtain ultrawide band with rejected $5.5 \mathrm{GHz}$ WLAN band.

\section{Antenna Structures}

Figure 1 illustrates the structures with detailed configurations of the proposed rejected $5.5 \mathrm{GHz}$ WLAN band UWB antenna, which is printed on a low cost $1.6 \mathrm{~mm}$ thick FR4 substrate material belonging to dielectric constant of 4.6 and loss tangent of 0.02. All the simulations have been performed using commercially available software package, high frequency structural simulator (HFSS), which is based on finite element method (FEM). Depending on the UWB antenna indicated in Figure 1(a), the proposed antenna has been designed. It is made of a circular patch with a radius of $R$ and a partial ground with a rectangular slot to acquire ultrawide bandwidth. The circular radiator is printed on the upper portion of the substrate fed by a microstrip line, where, on the lower portion of the substrate, the partial ground of $W \times L_{g}$ dimension is printed. The width at $M_{f}$ and the length at $9.09 \mathrm{~mm}$ are constant in order to acquire $50 \Omega$ input impedance. The port of the microstrip feed line is attached to a subminiature version A (SMA) connector. $g$ is indicated as the gap between the ground plane and the radiating patch. $W \times L$ is the thorough size of the proposed antenna.

Slotted CSRRs are implanted at the middle position of the circular radiator to create a notched WLAN band centered at $5.5 \mathrm{GHz}$. The CSRRs are made of two rectangular split ring slices to implement the characteristics of metamaterials. The length of the rectangular slotted rings is smaller than a half wavelength at the resonant frequency. This leads the rejected band to be generated centered at $5.5 \mathrm{GHz}$ WLAN band. However, the position of the CSRR plays an important role in order to determine the rejected $5.5 \mathrm{GHz}$ WLAN frequency band of the proposed antenna. In case of UWB notched antenna structure, the function of the filter is to create and control rejected band sharply. Because of exhibiting this characteristic, this CSRR design is a filter structure. In spite 

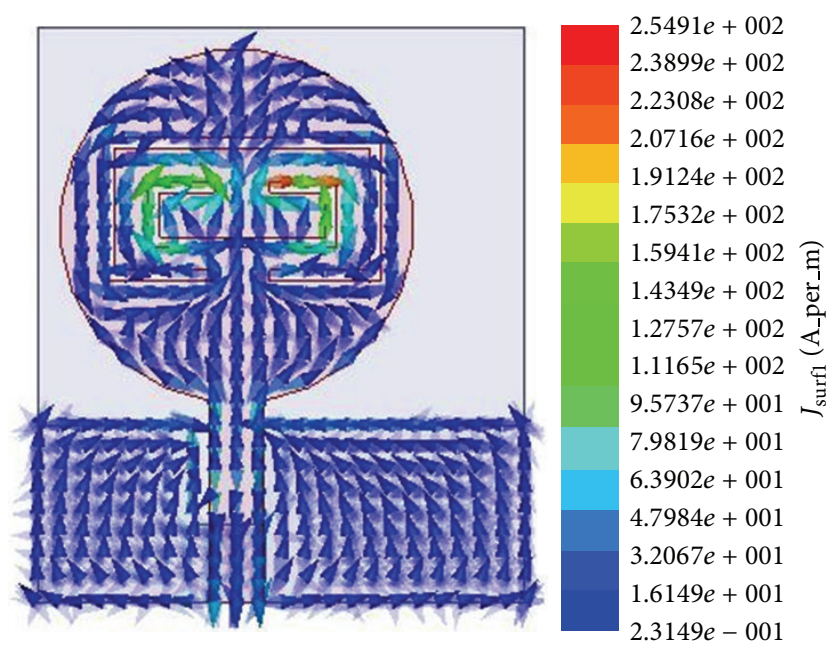

(a)
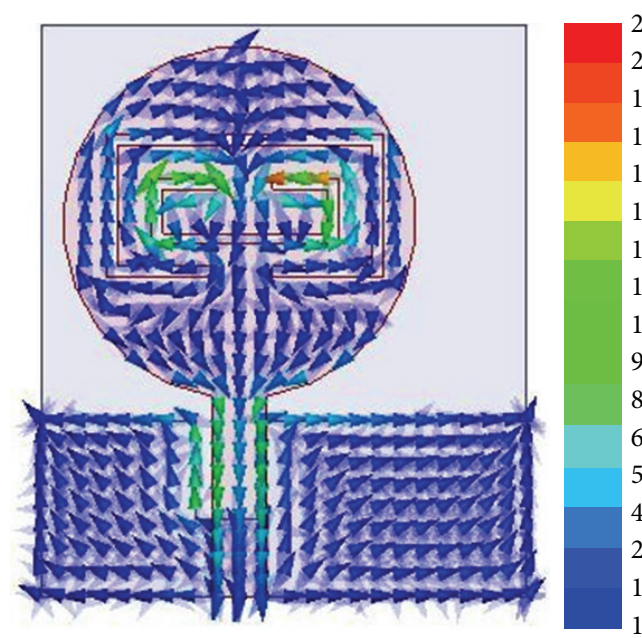

$2.1951 e+002$ $2.0580 e+002$ $1.9209 e+002$ $1.7838 e+002$ $1.6466 e+002$ $1.5095 e+002$ $1.3724 e+002$ छ $1.2353 e+002$ $1.0981 e+002$ $9.6102 e+001$ $8.2390 e+001$ 寻 $6.8677 e+001$ $5.4965 e+001$ $4.1252 e+001$ $2.7540 e+001$ $1.3827 e+001$ $1.1478 e-001$

(c)



(e)

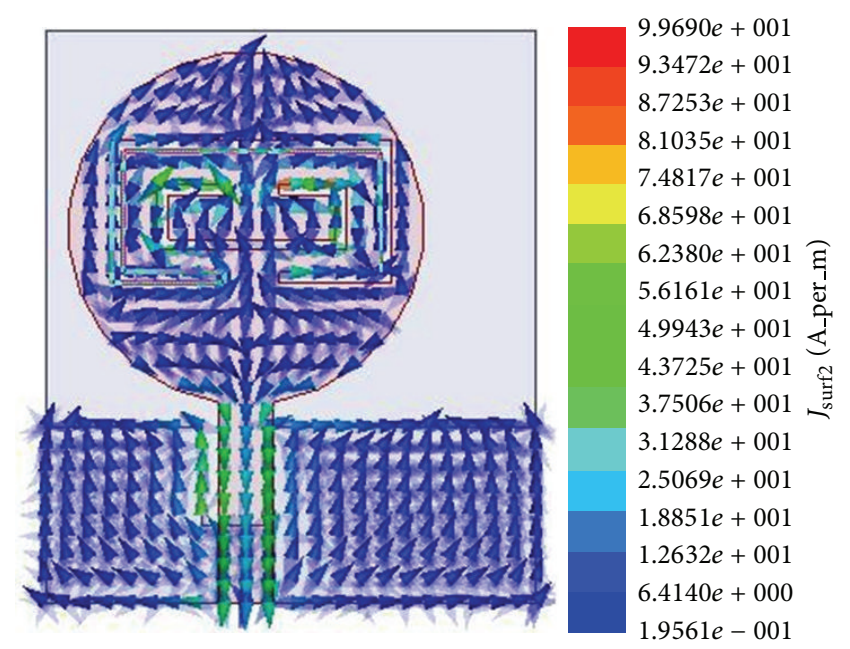

(b)

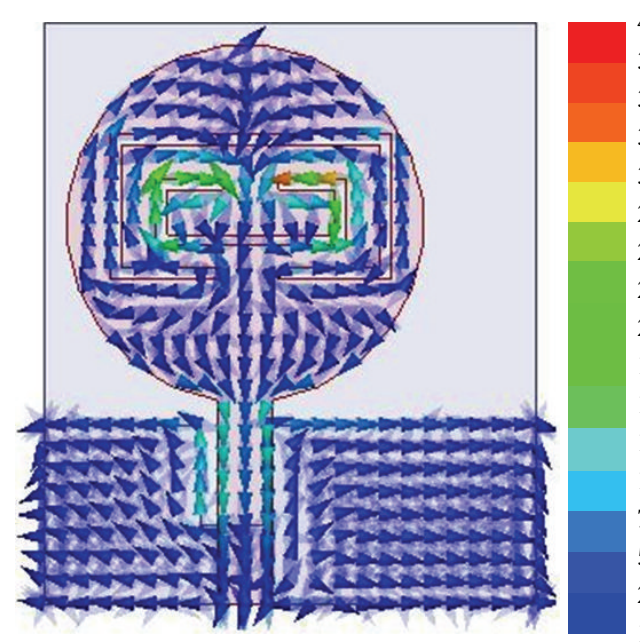

$4.0065 e+002$ $3.7562 e+002$ $3.5059 e+002$ $3.2556 e+002$ $3.0053 e+002$ $2.7551 e+002$ $2.5048 e+002$ ‡ $2.2545 e+002$ $2.0042 e+002$ i $1.7539 e+002$ $1.5037 e+002$ 苛 $1.2534 e+002$ $1.0031 e+002$ $7.5281 e+001$ $5.0253 e+001$ $2.5225 e+001$ $1.9648 e-001$

(d)



(f)

Figure 2: Surface current at $5.5 \mathrm{GHz}$ for different values of the phase angle (a) $0^{\circ}$, (b) $30^{\circ}$, (c) $60^{\circ}$, (d) $90^{\circ}$, (e) $120^{\circ}$, and (f) $150^{\circ}$. 




FIGURE 3: Extracted negative permittivity of CSRRs.

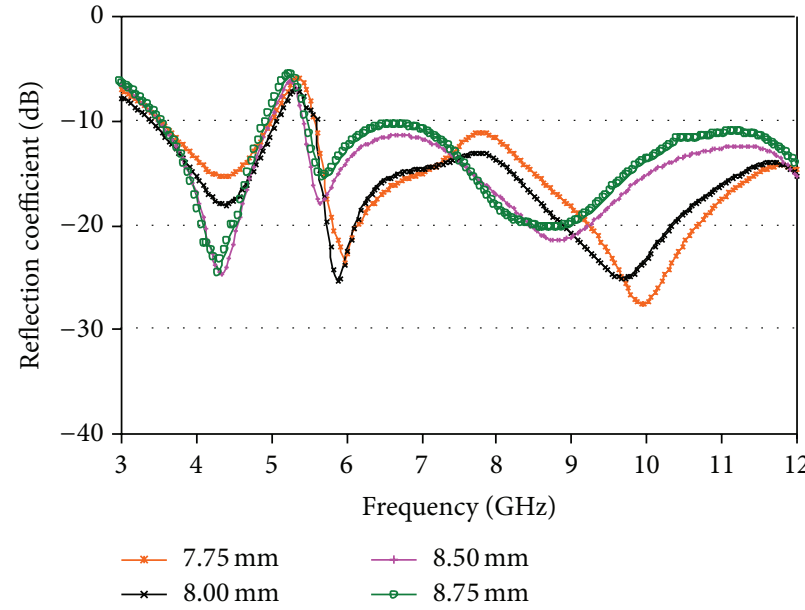

(a)

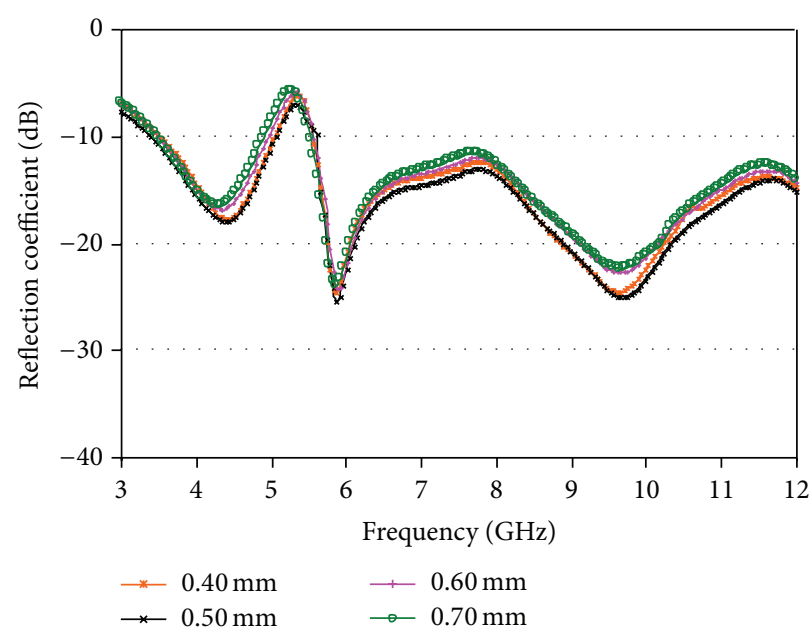

(c)

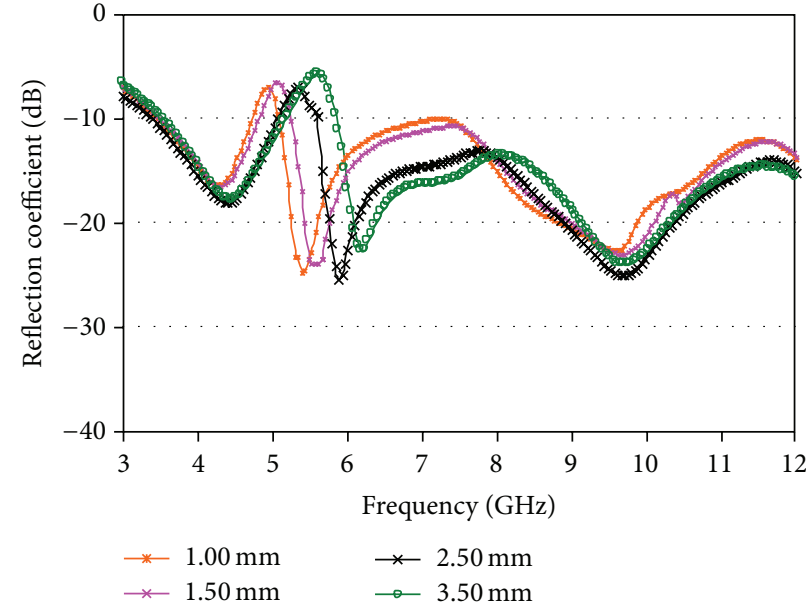

(b)

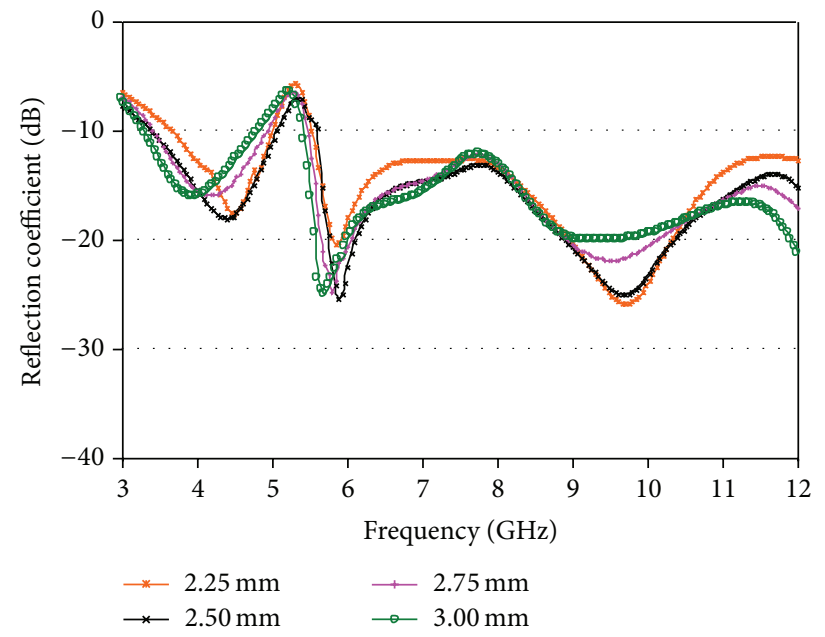

(d)

FIGURE 4: Effects for different values of (a) $R$, (b) $g_{1}$, (c) $d_{1}$, and (d) $M_{f}$ on the simulated reflection coefficient. 


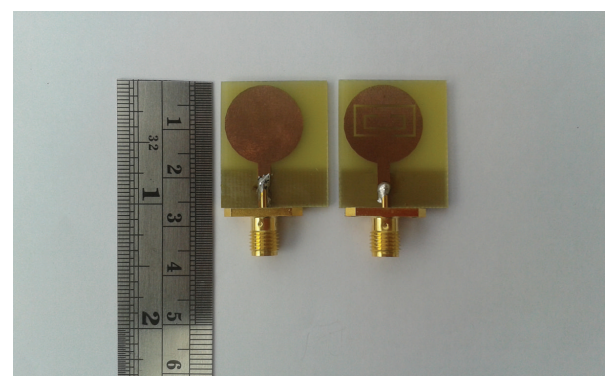

FIGURE 5: Photograph of the prototyped antenna.

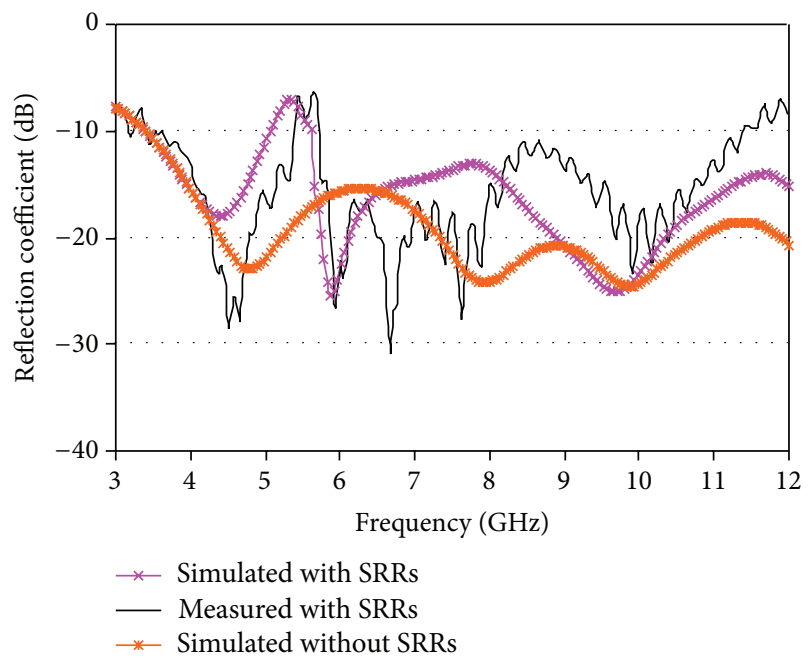

FIGURE 6: Measured and simulation reflection coefficient.

of implanting slotted CSRRs, the thorough antenna size is constant where, for the filter structure, excessive space is no longer demanded.

Figure 2 demonstrates the surface current with different values of the phase angle such as $0^{\circ}, 30^{\circ}, 60^{\circ}, 90^{\circ}, 120^{\circ}$, and $150^{\circ}$ to acquire some acuteness of generating the rejected band centered at $5.5 \mathrm{GHz}$ WLAN band. The surface current distribution of the antenna is acquired taking into account the optimized design parameters. It can be seen from Figure 2 that the concentration of the surface current distribution is very stable around the slotted split ring resonators and the feeding line. The flows of the current in the slotted CSRRs are inversed to the current flows in the outward edges of the radiator patch and the ground.

Consequently, the entire effective radiations are reduced enough or cancelled out completely, and an eliminated WLAN band is generated at $5.5 \mathrm{GHz}$ by virtue of high attenuation. The extracted negative permittivity of the CSRRs is shown in Figure 3, which is clearly seen the single negative metamaterial characteristic. The single negative metamaterials characteristics operations denote epsilon negative (ENG), which means that the permittivity characteristic is negative.

\section{Electromagnetic Performance Analysis}

The UWB antenna with removed $5.5 \mathrm{GHz}$ WLAN band using slotted CSRRs has been discussed with the parametric

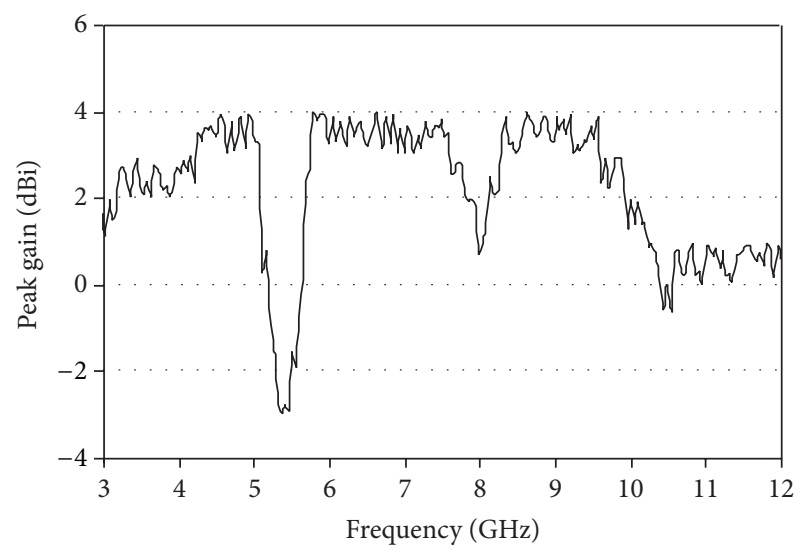

FIGURE 7: Measured peak gain of the proposed antenna.

analysis. The parametric analysis is executed in order to review the effects of design parameters, which are detailed as follows. All the parameters are retained constant in the simulation without the interested parameter. The radius of the circular patch for different values of $R$ is indicated in Figure 4(a). The resonance of the eliminated band is found at $5.5 \mathrm{GHz}$ using $8.00 \mathrm{~mm}$ as the value of $R$. If the value of $R$ is increased or decreased, the resonance of the eliminated band is shifted sharply. Therefore, the optimized value of $R$ is $8.00 \mathrm{~mm}$. Figure 4(b) demonstrates the gap among the two edges of the slotted rings for different values of $g_{1}$. The resonance of the eliminated band switches from lower frequency up to a definite value, since the values of $g_{1}$ rise. Hence, $2.5 \mathrm{~mm}$ is the optimized value.

Figure 4(c) depicts the impedance properties of the proposed antenna for different values of $d_{1}$, which is the thickness of the CSRR. It is found that the resonance is on the lower frequency using $0.40 \mathrm{~mm}$, the value of $d_{1}$, while the resonance is observed on the higher frequency using $0.60 \mathrm{~mm}$ and $0.70 \mathrm{~mm}$. The notched $5.5 \mathrm{GHz}$ WLAN band is seen with $0.50 \mathrm{~mm}$, which is desired. The impedance properties with different values of the feed line width, $M_{f}$, are shown in Figure 4(d). The eliminated $5.5 \mathrm{GHz}$ WLAN band is acquired, when the width of the feed line is $2.5 \mathrm{~mm}$. Otherwise, the eliminated band is shifted on lower frequency or higher frequency using $2.25 \mathrm{~mm}, 2.75 \mathrm{~mm}$, and $3.00 \mathrm{~mm}$. It is realized from Figure 4 that the eliminated $5.5 \mathrm{GHz}$ WLAN band is originated and regulated by virtue of slotted CSRRs. The optimized values of the designed parameters are as follows: $W=22 \mathrm{~mm}, L=26 \mathrm{~mm}, R=8 \mathrm{~mm}, M_{f}=2.5 \mathrm{~mm}$, $L_{g}=8 \mathrm{~mm}, g=1.09 \mathrm{~mm}, D_{g}=11.75 \mathrm{~mm}, D_{P}=5 \mathrm{~mm}$, $S_{1}=6.5 \mathrm{~mm}, S_{2}=12.5, g_{1}=2.5 \mathrm{~mm}, g_{2}=1.5 \mathrm{~mm}$, and $d_{1}=0.5 \mathrm{~mm}$.

\section{Experimental Verification}

A vector network analyzer (model number: Agilent E8362C) has been used for the measurements in a standard farfield testing environment. The prototype of the proposed antenna is shown in Figure 5. The simulated and measured reflection coefficient of the mentioned antenna is illustrated in Figure 6 with reflection coefficient without SRRs. The 


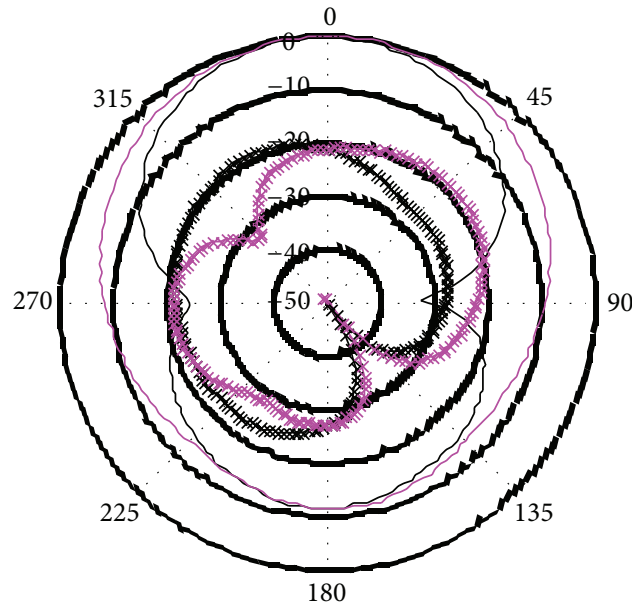

(a)



(c)

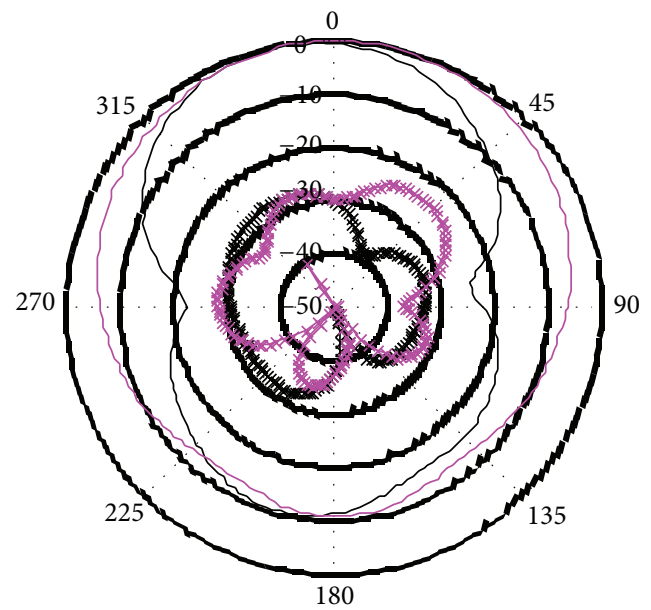

(b)



(d)

FIGURE 8: Measured radiation patterns at (a) 4.5, (b) 5.5, (c) 6.0, and (d) $6.7 \mathrm{GHz}$.

eliminated $5.5 \mathrm{GHz}$ WLAN band is realized in the reflection coefficient properties belonging to a bandwidth of $495 \mathrm{MHz}$. It covers an ultrawide frequency band from $3.45 \mathrm{GHz}$ to more than $12 \mathrm{GHz}$ with an eliminated $5.5 \mathrm{GHz}$ WLAN band. The incompatibility between measurement and simulation is predominantly owing to fabrication faults in the antenna design.

Figure 7 indicates the measured peak gain of the reported antenna. The gain drops swiftly in the region of the eliminated $5.5 \mathrm{GHz}$ WLAN band, as maximum radiated power is backed to the antenna at the notched band. The measured gain is $-3 \mathrm{dBi}$ in case of the eliminated band for WLAN. The antenna discloses stable gain without the operating frequency of the notched band.

Figure 8 displays the measured radiation patterns at 4.5 GHz, 5.5 GHz, 6.0 GHz, and $6.7 \mathrm{GHz}$ with E-plane and $\mathrm{H}$-plane. In order to demonstrate copolarization and cross polarization, two-dimensional $(2 \mathrm{D})$ radiation patterns were resorted at resonances $4.5 \mathrm{GHz}, 5.5 \mathrm{GHz}, 6.0 \mathrm{GHz}$, and
6.7 $\mathrm{GHz}$, respectively. $E_{\theta}$ represents the copolarization properties, and $E_{\varphi}$ represents the cross polarization properties. The $y z$ coordinates are taken into account as the E-plane and $x z$ coordinates as the $\mathrm{H}$-plane. The cross polarization dimension is smaller than the copolarization dimension on both the $\mathrm{H}$-plane and E-plane at the resonances $4.5 \mathrm{GHz}$, $5.5 \mathrm{GHz}, 6.0 \mathrm{GHz}$, and $6.7 \mathrm{GHz}$, respectively. It is observed that the proposed antenna exhibits better broadside radiation features and considerable front-to-back ratio with low cross polarization, which leads to symmetric and nearly omnidirectional radiation pattern. At the eliminated $5.5 \mathrm{GHz}$ WLAN band, the gains are markedly restrained in all the directions, which announce the effect of slotted CSRRs.

The measured phase variation of the input impedance is shown in Figure 9. It is overlooked that the phase variation is linear over the entire operating frequency bands without the eliminated $5.5 \mathrm{GHz}$ WLAN band.

The antenna radiation efficiency is shown in Figure 10. From Figure 10, it can be found that the antenna acquired 
TABLE 1: Comparisons between existing and proposed band-rejected UWB antennas.

\begin{tabular}{lcc}
\hline Antennas & $\begin{array}{c}\text { Rejected band } \\
(\mathrm{GHz})\end{array}$ & $\begin{array}{c}\text { Dimensions } \\
\left(\mathrm{mm}^{2}\right)\end{array}$ \\
\hline$[18]$ & $5.12-6.08$ & $30 \times 35$ \\
{$[22]$} & $4.85-6.04$ & $30 \times 36$ \\
{$[23]$} & $5.15-5.825$ & $30 \times 39.3$ \\
{$[17]$} & Centre at 5.00 & $35 \times 30$ \\
{$[24]$} & $5.00-6.00$ & $35 \times 35$ \\
$\begin{array}{l}\text { Proposed } \\
\text { antenna }\end{array}$ & $5.41-5.72$ & $22 \times 26$ \\
\hline
\end{tabular}

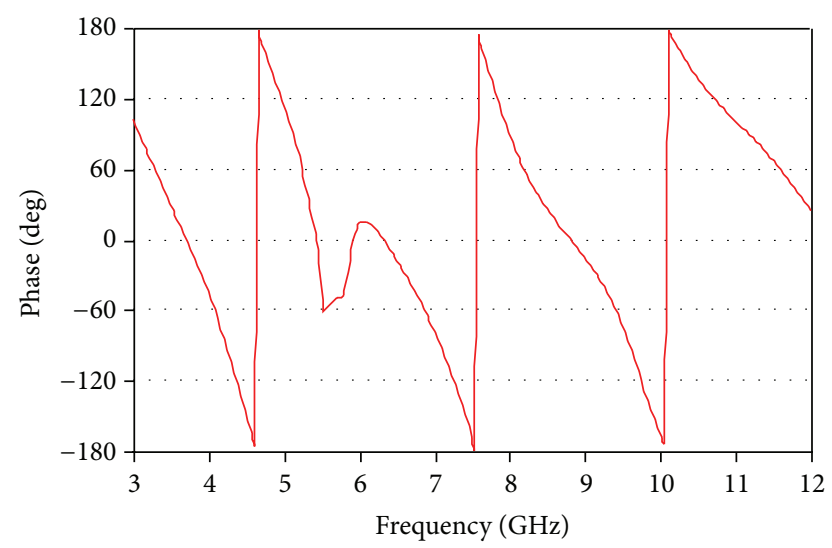

FIGURE 9: Measured phase variation of the input impedance.

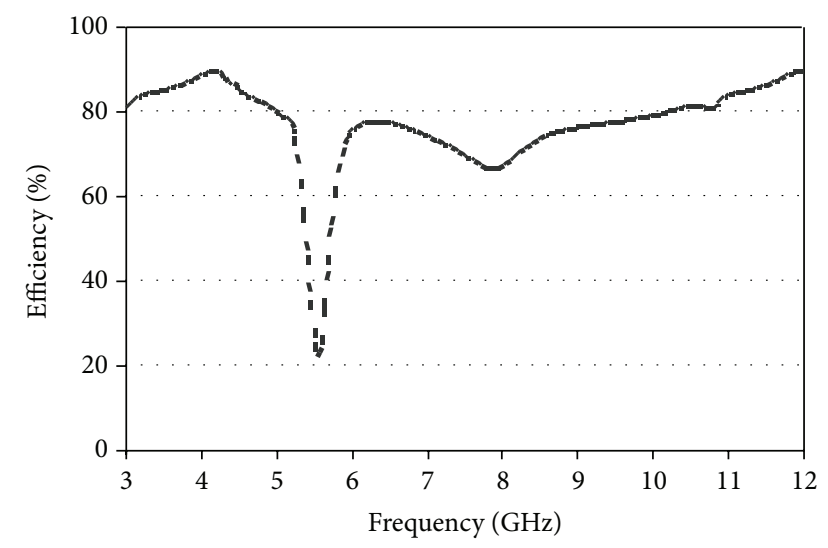

FIGURE 10: Radiation efficiency of the proposed antenna.

good radiation efficiency throughout the entire UWB range without $5.5 \mathrm{GHz}$ rejected band. The efficiency reduces sharply at $5.5 \mathrm{GHz}$ band that illustrates the effect of rejected band. The comparisons between existing and proposed band-rejected UWB antennas are listed in Table 1, which bears testimony to the compact profile of the proposed antenna.

\section{Conclusion}

A compact UWB antenna with rejected 5.5 GHz WLAN band using complementary split ring resonators (CSRRs) has been presented and studied in this paper. The antenna is composed of a circular patch and a partial ground with a thorough size of $22 \times 26 \mathrm{~mm}^{2}$. The slotted CSRRs are inserted in the circular patch to observe notched $5.5 \mathrm{GHz}$ WLAN band characteristics. The proposed antenna acquired better UWB execution with notched band properties to lighten the interference problem created from WLAN. The properties of wide bandwidth, nearly omnidirectional radiation patterns, and compact profile satisfactory gain with rejection of rejected $5.5 \mathrm{GHz}$ WLAN band originates the proposed antenna as a milestone for UWB applications.

\section{Conflict of Interests}

The authors declare that there is no conflict of interests regarding the publication of this paper.

\section{References}

[1] J. B. Pendry, A. J. Holden, D. J. Robbins, and W. J. Stewart, "Magnetism from conductors and enhanced nonlinear phenomena," IEEE Transactions on Microwave Theory and Techniques, vol. 47, no. 11, pp. 2075-2084, 1999.

[2] F.-Y. Meng, Q. Wu, B.-S. Jin, H.-L. Wang, and J. Wu, “Design and double negative property verification of $\mathrm{C}$ band left-handed metamaterial," Microwave and Optical Technology Letters, vol. 48, no. 9, pp. 1732-1736, 2006.

[3] K. Zhang, Q. Wu, J. H. Fu, F. Y. Meng, and L. W. Li, "Metamaterials with tunable negative permeability based on mie resonance," IEEE Transactions on Magnetics, vol. 48, no. 11, pp. 4289-4292, 2012.

[4] M. F. Wu, F. Y. Meng, Q. Wu, J. Wu, and J. C. Lee, "An approach for small omnidirectional microstrip antennas based on the backward waves of double negative metamaterials," Applied Physics A: Materials Science and Processing, vol. 87, no. 2, pp. 193-198, 2007.

[5] Federal Communications Commission, Revision of Part 15 of the Commission's Rules Regarding Ultra-Wideband Transmission System From 3. 1 to 10. $6 \mathrm{GHz}$, Federal Communications Commission, T-Docket, Washington, DC, USA, 2002.

[6] M. R. I. Faruque, M. T. Islam, and N. Misran, "Analysis of electromagnetic absorption in mobile phones using metamaterials," Electromagnetics, vol. 31, no. 3, pp. 215-232, 2011.

[7] J. Anguera, A. Andújar, M. C. Huynh, C. Orlenius, C. Picher, and C. Puente, "Advances in antenna technology for wireless handheld devices," International Journal on Antennas and Propagation, vol. 2013, Article ID 838364, 25 pages, 2013.

[8] M. R. I. Faruque, M. T. Islam, and N. Misran, "Effect of human head shapes for mobile phone exposure on electromagnetic absorption," Informacije MIDEM, vol. 40, no. 3, pp. 232-237, 2010.

[9] J. W. Jayasinghe and D. N. Uduwawala, "A novel miniature multi-frequency broadband patch antenna for WLAN applications," in Proceedings of the IEEE 8th International Conference on Industrial and Information Systems (ICIIS '13), pp. 361-363, Peradeniya, Sri Lanka, August 2013.

[10] Y.-J. Ren and K. Chang, "An annual ring antenna for UWB communications," IEEE Antennas and Wireless Propagation Letters, vol. 5, no. 1, pp. 274-276, 2006.

[11] H.-Y. Lai, Z.-Y. Lei, Y.-J. Xie, G.-L. Ning, and K. Yang, "UWB antenna with dual band rejection for WLAN/WIMAX bands 
using CSRRs," Progress in Electromagnetics Research Letters, vol. 26, pp. 69-78, 2011.

[12] N. C. Azenui and H. Y. D. Yang, "A Printed crescent patch antenna for ultrawideband applications," IEEE Antennas and Wireless Propagation Letters, vol. 6, pp. 113-116, 2007.

[13] R. Azim, M. T. Islam, and N. Misran, "Compact taperedshape slot antenna for UWB applications," IEEE Antennas and Wireless Propagation Letters, vol. 10, pp. 1190-1193, 2011.

[14] Q. Wu, F.-Y. Meng, J. Wu, and L.-W. Li, "Broadband characteristics investigation of waves in a left-handed miniaturized waveguide loaded with ISRRs," Applied Physics A: Materials Science and Processing, vol. 87, no. 2, pp. 305-308, 2007.

[15] M. F. Wu, F. Y. Meng, Q. Wu, J. Wu, and L. W. Li, "A compact equivalent circuit model for the SRR structure in metamaterials," in Proceedings of the Asia-Pacific Microwave Conference (APMC '05), pp. 4-7, December 2005.

[16] L. Zhu, F. Y. Meng, F. Zhang et al., "An ultra-low loss split ring resonator by suppressing the electric dipole moment approach," Progress in Electromagnetics Research, vol. 137, pp. 239-254, 2013.

[17] S.-J. Wu, C.-H. Kang, K.-H. Chen, and J.-H. Tarng, "Study of an ultrawideband monopole antenna with a band-notched open-looped resonator," IEEE Transactions on Antennas and Propagation, vol. 58, no. 6, pp. 1890-1897, 2010.

[18] H.-W. Liu, C.-H. Ku, T.-S. Wang, and C.-F. Yang, “Compact monopole antenna with band-notched characteristic for UWB applications," IEEE Antennas and Wireless Propagation Letters, vol. 9, pp. 397-400, 2010.

[19] T.-N. Chang and M.-C. Wu, "Band-notched design for UWB antennas," IEEE Antennas and Wireless Propagation Letters, vol. 7, pp. 636-640, 2008.

[20] D. H. Lee, H.-Y. Yang, and Y.-K. Cho, "Tapered slot antenna with band-notched function for ultrawideband radios," IEEE Antennas and Wireless Propagation Letters, vol. 11, pp. 682-685, 2012.

[21] R. A. Formato, "VSO-optimized dipole-loaded monopole," British Journal of Applied Science \& Technology, vol. 4, no. 6, pp. 912-928, 2014.

[22] C. Yoon, W.-J. Lee, W.-S. Kim, H.-C. Lee, and H.-D. Park, "Compact band-notched ultra-wideband printed antenna using inverted L-slit," Microwave and Optical Technology Letters, vol. 54, no. 1, pp. 143-144, 2012.

[23] Y. F. Weng, S. W. Cheung, and T. I. Yuk, "Compact ultrawideband antennas with single band-notched characteristic using simple ground stubs," Microwave and Optical Technology Letters, vol. 53, no. 3, pp. 523-529, 2011.

[24] Y.-C. Lin and K.-J. Hung, "Compact ultrawideband rectangular aperture antenna and band-notched designs," IEEE Transactions on Antennas and Propagation, vol. 54, no. 11, pp. 30753081, 2006. 

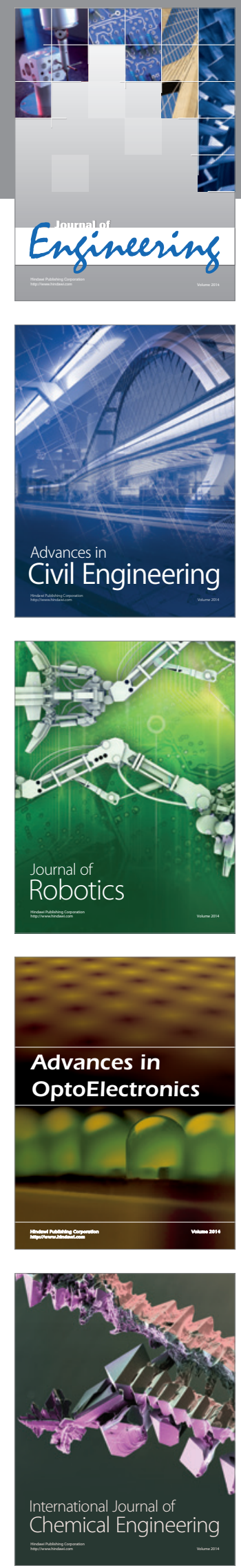



The Scientific World Journal
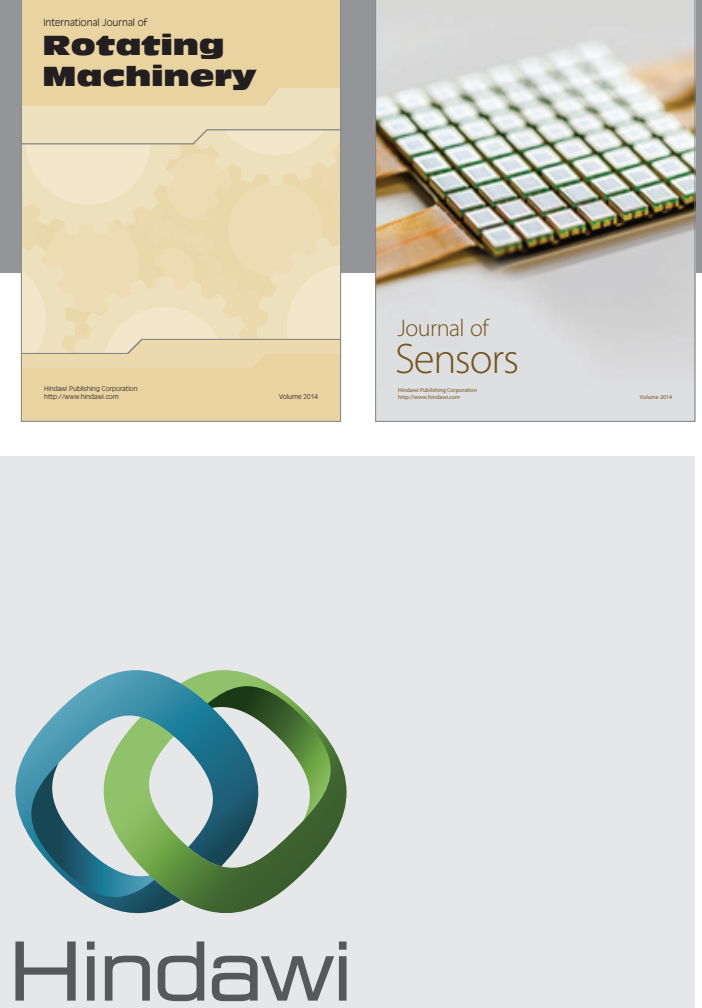

Submit your manuscripts at http://www.hindawi.com

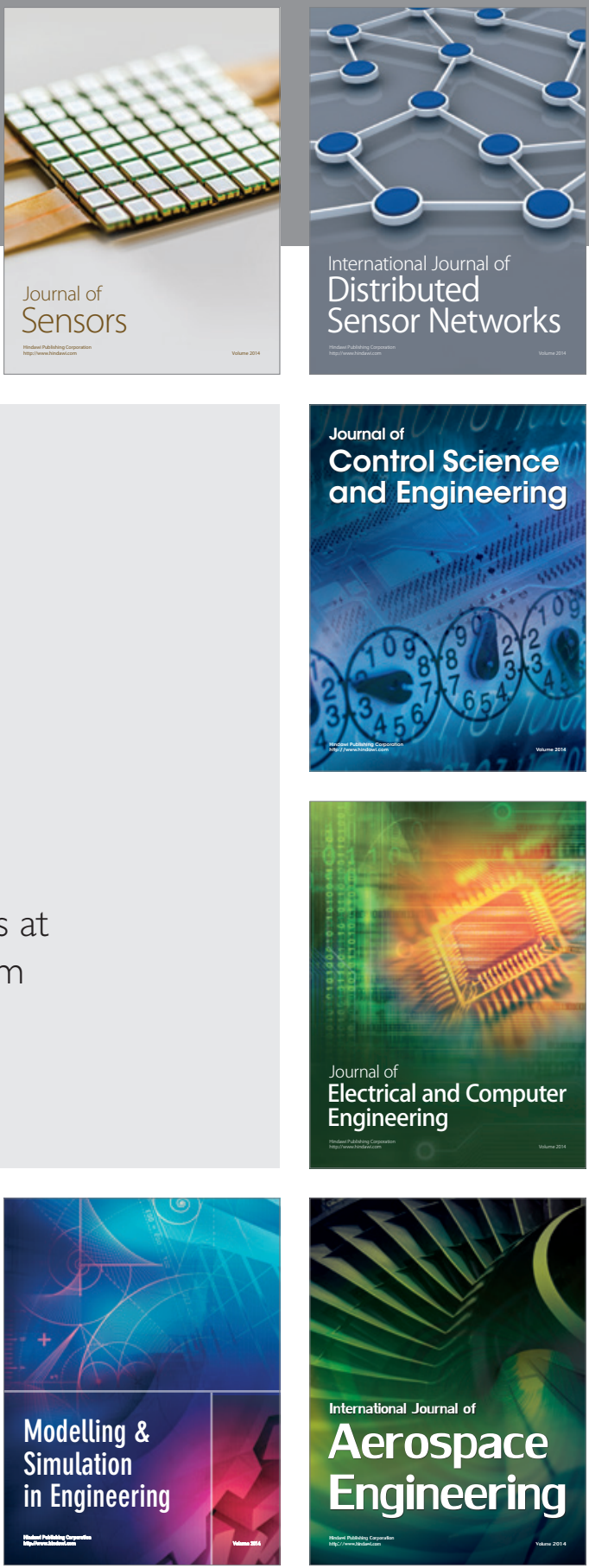

Journal of

Control Science

and Engineering
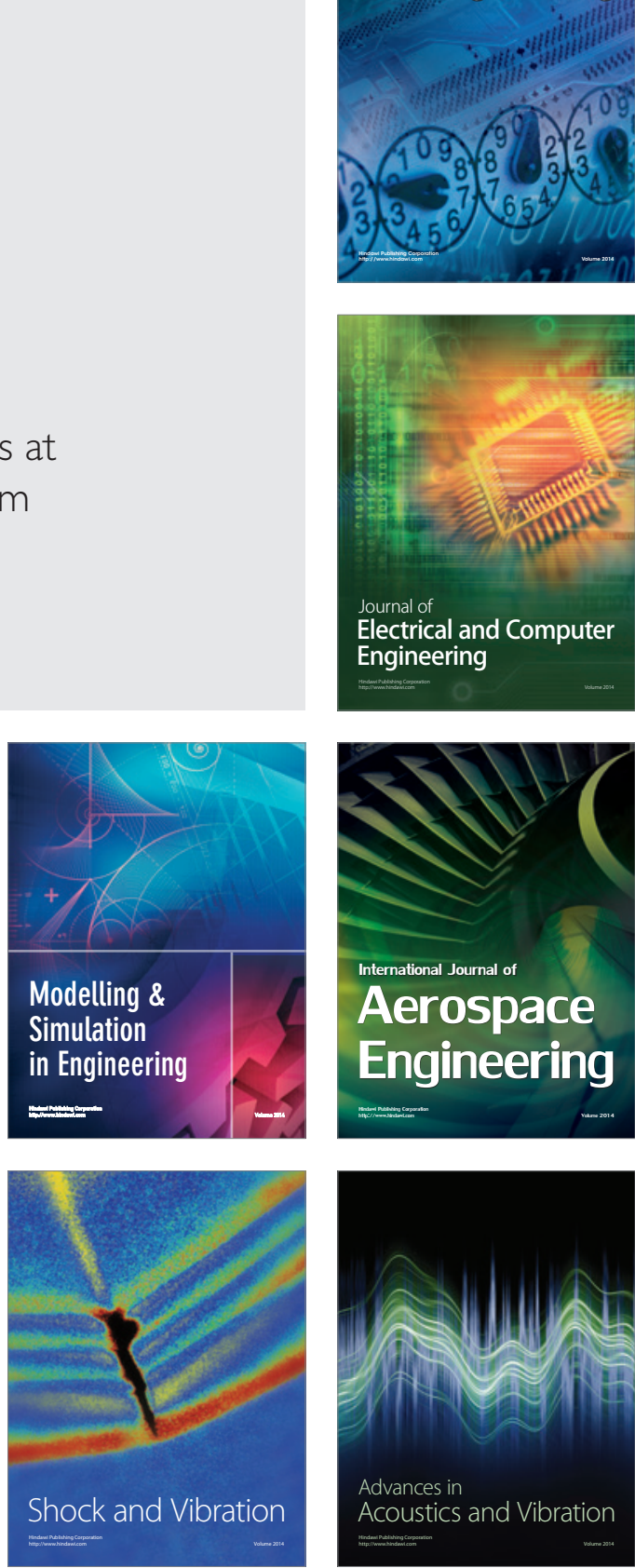